\section{Use of the 6-minute walk/run test to predict peak oxygen uptake in adolescents}

\section{Teste de corrida/caminhada de 6 minutos para a predição do consumo de oxigênio de pico em adolescentes}

Gabriel Gustavo Bergmann

Mauren Lúcia de Araújo Bergmann

Antônio Adolfo Mattos de Castro'

Thiago Del'Corona Lorenzi ${ }^{2}$

Eraldo dos Santos Pinheiro

Rodrigo Baptista Moreira ${ }^{3}$

Alexandre Carriconde Marques ${ }^{4}$

Adroaldo Gaya ${ }^{2}$

\section{ABSTRACT}

This study aimed to create an equation to predict peak oxygen uptake from data of the 6-minute walk/run test and demographic and anthropometric variables in adolescents. The results of the 6-minute walk/run (6WRT), peak oxygen uptake, height, body weight and body mass index (BMI) in 125 adolescents age 10 to 14, of which 66 were female, were assessed. They were divided into a validation and a cross-validation group. A linear regression analysis was conducted to assess the associations between the independent variables 6WRT, age, gender, anthropometric measurements and the dependent variable peak oxygen uptake in the validation group. The Bland-Altman method was used to test agreement between measured and estimated values. It was found that the best model to predict peak oxygen uptake included the 6-minute walk/run test, BMI, and gender. These variables presented a multiple correlation coefficient of 0.77 and a standard error of estimate of $3.99[(\mathrm{~mL} / \mathrm{kg}) / \mathrm{min}]$. The accuracy of the model was tested by applying the equation created in the validation group to the cross-validation group and total sample. The Bland-Altman method results did not indicate any systematic bias or heteroscedasticity in both the validation and cross-validation groups. In conclusion, our multiple regression equation [peak oxygen uptake $=41.946+0.022(6 \mathrm{WRT})-0.875(\mathrm{BMI})$ +2.107 (gender)] is adequate for predicting peak oxygen uptake in adolescents age 10 to 14 .

\section{KEYWORDS}

Cardiorespiratory fitness; field tests; adolescents; Bland-Altman.

\section{RESUMO}

Este estudo objetivou criar uma equação para a predição do consumo de oxigênio de pico em adolescentes a partir do teste de corrida/caminhada de 6 minutos, variáveis demográficas e antropométricas. Os resultados do teste de corrida/caminha de 6 minutos (6-min), consumo de oxigênio de pico, estatura, massa corporal e indice de massa corporal (IMC) de 125 adolescentes de 10 a 14 anos de idade (66 moças) foram avaliados. A amostra foi dividida em um grupo validação e um grupo validação cruzada. A análise de regressão linear múltipla foi utilizada para analisar as associações entre o 6-min, idade, sexo e medidas antropométricas (variáveis independentes) e o consumo de oxigênio de pico (variável dependente) no grupo validação. O diagrama de Bland-Altman foi utilizado para testar a concordância entre os valores medidos e estimados. $O$ melhor modelo encontrado para predizer o consumo de oxigênio de pico incluiu o 6-min, o IMC e o sexo. Estas variáveis apresentaram um coeficiente de correlação múltipla de 0,77 e um erro padrão de estimativa de 3,99 [(mL/kg)/min]. A acurácia do modelo foi testada aplicando a equação criada no grupo validação no grupo validação cruzada e em toda a amostra. Os resultados do diagrama de Bland-Altman não indicaram erro sistemático e heteroscedasticidade tanto no grupo validação quanto no grupo validação cruzada. Em conclusão, a equação proposta [consumo de oxigênio de pico $=41,946+0,022(6$-min) $-0,875($ IMC) +2.107 (sexo) é adequada para predição do consumo de oxigênio de pico em adolescentes de 10 a 14 anos de idade.

\section{PALAVRAS-CHAVE}

Aptidão cardiorrespiratória; Testes de campo; Adolescentes; Bland-Altman.
Rev Bras Ativ Fis Saúde p. 64-73

DOI:

http://dx.doi.org/10.12820/rbafs.v.19n1p64

1 Federal University of Pampa (UNIPAMPA), Health Science Center, Uruguaiana, Brazil;

2 Federal University of Rio Grande do Sul (UFRGS), Physical Education College, Porto Alegre, Brazil

3 Lutheran University of Brazil (ULBRA), Physical Education College, São Jerônimo, Brazil;

4 Federal University of Pelotas (UFPel), Physical Education College, Pelotas, Brazil 


\section{INTRODUCTION}

Cardiorespiratory fitness (CRF) is a major marker of health in children and adolescents. ${ }^{1-2}$ This piece of evidence supports the importance of the assessing and monitoring this physical fitness component during childhood and adolescence. It is thus key to have valid alternative approaches available to measure CRF.

The assessment of peak oxygen uptake $\left(\dot{V} \mathrm{O}_{2 \text { peak }}\right)$ using direct methods (laboratory tests) is the gold standard to measure CRF in children and adolescents. However, it has limited use in school- and population-based studies because it is a time-consuming costly test requiring trained staff. ${ }^{3}$ Indirect field tests are an alternative approach to this test.

Several indirect field tests have been validated to predict $\dot{\mathrm{VO}}_{2 \text { peak }}$ in children and adolescents. The two most widely used tests are the 1-mile walk test (1-MWT) and the 20-meter shuttle run test (SRT). The duration of these tests varies from individual to individual but they usually last more than eight

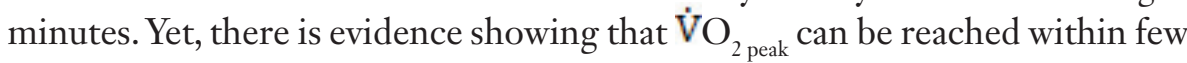
minutes in children and adolescents. ${ }^{4,5}$ Thus, indirect field tests with a shorter duration than 1-MWT and SRT could be used to predict $\dot{V} \mathrm{O}_{2 \text { peak }}$ in children and adolescents. This is supported by Castro-Pinero et al. ${ }^{3}$ who showed that the half-mile walk test $(1 / 2-M W T)$ along with gender and body mass index (BMI) can be used to predict $\dot{\mathrm{VO}}_{2 \text { peak }}$.

Similar to the $1-M W T$, the purpose of the $1 / 2-M W T$ is to walk/run as fast as possible for 0.5 mile, so time to complete the test is different among individuals. When CRF is assessed as part of fitness test batteries such as ALPHA, ${ }^{6}$ EUROFIT, ${ }^{7}$ Fitnessgram ${ }^{8}$, MOPER Fitness test, ${ }^{9}$ and PROESP,${ }^{10}$ the collection of data in school-based studies can be affected because some individuals may, let us say, complete the test in 5 minutes while others may take 10 minutes to complete it. Thus, an alternative approach would be to use indirect field tests with a short duration but with the purpose of covering the longest distance within an allotted period so that all individuals would complete the test within the same time. This modified approach makes it easier planning and management of collected data in these studies. The aim of this study was to create an equation to predict $\dot{\mathrm{VO}}_{2 \text { peak }}$ using data from the 6-minute walk/ run $(6 \mathrm{WRT})$ in adolescents.

\section{METHODS}

This was part of a large study, "Cardiorespiratory field tests: validation and metabolic determinants in children and adolescents," approved by the Universidade Federal do Rio Grande do Sul research ethics committee (protocol number 2005461). There were assessed 125 students age 10 to 14, of which 66 were female, from three schools in the city of Porto Alegre, Brazil. The participants were randomly divided into a validation (70\% of total sample; 87 students) and a cross-validation group (38 students). None of them were members of competitive sports team but they all attended physical education programs at their schools. They volunteered to participate in the study and their parents/guardians were asked to sign an informed consent form before entering the study.

In addition to age and gender, we assessed $\dot{V} \mathrm{O}_{2 \text { peak }}, 6 \mathrm{WRT}$ and anthropometric variables in all participants. The anthropometric measures included 
height and body weight. Height measurements were taken with a portable stadiometer $\left(\right.$ Seca $^{\circledR}$, TBW, São Paulo, Brazil) and recorded in centimeters and rounded to the nearest millimeter. Body weight measurements were taken with a portable digital scale and rounded to the nearest 100 grams $\left(P l e n n a^{\circledR}\right.$, São Paulo, Brazil). Standard guidelines ${ }^{11}$ were followed to measure these two anthropometric variables. Then body mass index (BMI) was calculated by dividing body weight in kilograms by the squared of height in meters $\left(\mathrm{kg} / \mathrm{m}^{2}\right)$.

$\dot{V} \mathrm{O}_{2 \text { peak }}$ was assessed with a MedGraphics Cardiorespiratory Diagnostic System (MGC/CPX-D model, St. Louis, USA) ergospirometer. To ensure the quality of measurements, the equipment was calibrated before each evaluation under controlled environmental conditions (temperature, barometric pressure and relative humidity of air). The temperature of the air-conditioned examination room was kept between 20 and $23^{\circ} \mathrm{C}$. The pneumotachograph flow-volume device was calibrated with a 3 -liter calibration syringe. To ensure stability, gas was manually injected and ejected five times using different speeds. Finally, the gas analyzer was calibrated using two known gas mixture cylinders (standard reference and calibration). The standard reference cylinder contained a mixture of $5 \% \mathrm{CO}_{2}$ and $12 \% \mathrm{O}_{2}$ and the gas calibration one contained a mixture of $21 \% \mathrm{O}_{2}$, both with super dry nitrogen.

As a preparation for testing, participants were fitted with a heart rate monitor and an ergoespirometric mask. A symptom-limited treadmill stress protocol was followed to measure $\dot{V} \mathrm{O}_{2 \text { peak }}$. First, participants remained at rest for one minute and then were asked to walk on the treadmill at a speed of 6 kilometers per hour at no incline for a two-minute warm-up period. After warm-up, the treadmill speed was increased at half a kilometer per hour every 30 seconds (progressive ramp protocol). The participants were constantly encouraged to achieve their maximum performance. As they reached their maximum performance, the test ended and the treadmill speed was decreased to 5 kilometers per hour to slow down their heart rate and pulmonary ventilation. ${ }^{12}$ $\dot{V} \mathrm{O}_{2 \text { peak }}$ measures were considered adequate when at least three of the following four criteria were met: ${ }^{13}$ a) the participant seems exhausted or unable to keep running at the current speed; b) the participant's heart rate reached $90 \%$ of its predicted maximum; c) respiratory exchange ratio was equal to or greater than one; and/or d) oxygen uptake plateau was reached. $\dot{V} \mathrm{O}_{2 \text { peak }}$ was recorded as an absolute (liter per minute $-\mathrm{L} / \mathrm{min}$ ) and a relative measure to body weight [milliliter per kilogram per minute $-(\mathrm{mL} / \mathrm{kg}) / \mathrm{min}$ ] values.

The purpose of the $6 \mathrm{WRT}$ was to run the longest distance within 6 minutes. The test results were recorded in meters. As in the incremental exercise test, participants were encouraged to achieve their maximum performance in the 6WRT.

The data collection process consisted of 4 steps. In step 1, the study objectives and procedure were explained to school staff and students and a start date was scheduled. In step 2, we enrolled students by age and gender for the 6WRT. They were given instructions and performed the test. Step 3 took place 3 to 4 days later when all students were retested. The results of the second 6WRT were included in the data analysis. The last step 4 took place 5 to 7 days later when anthropometric variables and $\dot{V} \mathrm{O}_{2 \text { peak }}$ were assessed at the exercise laboratory of the study site.

For data analysis, it was first verified that the data was normally distributed. Descriptive statistics (mean and standard deviation) were used to summa- 
rize it and the independent t-test was performed to identify differences in the variables studied by gender and between the validation and cross-validation groups. Pearson's correlation coefficient was used to test the association between the variables and a linear regression analysis was conducted to estimate $\dot{\mathrm{V}} \mathrm{O}_{2 \text { peak }}$ in the validation group. All variables with statistically significant correlation $(p<0.05)$ with $\dot{V} \mathrm{O}_{2 \text { peak }}$ were included in the linear regression analysis. To verify the systematic accuracy of the equation created in the validation group, it was applied in the cross-validation group and total sample. A simple linear regression model was used to estimate the validity correlation (correlation between measured and estimated $\dot{V} \mathrm{O}_{2 \text { peak }}$ values) and the standard error of estimate (SEE). The differences between measured and estimated mean $\dot{V} \mathrm{O}_{2 \text { peak }}$ values in the validation and cross validation groups and total sample were assessed by paired sample t-test (systematic bias). The Bland-Altman method was used to assess the agreement between measured and estimated $\dot{V} \mathrm{O}_{2 \text { peak }}$ values in both groups; and Pearson's correlation coefficient to assess the association between the difference and the magnitude of measurement (heteroscedasticity). All statistical analyses were performed with the use of the Statistical Package for the Social Sciences (SPSS ${ }^{\circledR}$, SPSS Inc., IBM, Chicago, IL, US) for Windows version 20.0; the statistical significance was set at $5 \%$.

\section{RESULTS}

Table 1 shows the overall characteristics of participants by gender in the validation and cross-validation groups. There were no significant differences by gender except for BMI $(p>0.05)$. For all other variables males had higher mean values than females $(p<0.05)$. No statistically differences were found between validation and cross-validation groups for all variables studied $(p>0.05)$. The Pearson's correlation coefficient showed that $\dot{V} \mathrm{O}_{2 \text { peak }}$ is inversely correlated to BMI $(\mathrm{r}=-0.38 ; p<0.05)$ and directly correlated to $6 \mathrm{WRT}(\mathrm{r}=0.54 ; p<0.05)$ in total sample.

TABLE 1 - Overall characteristics of participants by gender in the validation and cross-validation groups.

\begin{tabular}{|c|c|c|c|c|c|c|c|c|c|c|c|c|c|c|c|}
\hline & \multicolumn{3}{|c|}{ Total } & \multicolumn{3}{|c|}{ Male } & \multicolumn{3}{|c|}{ Female } & \multicolumn{3}{|c|}{ Validation group } & \multicolumn{3}{|c|}{ Cross-validation group } \\
\hline & $\mathrm{n}$ & Mean & SD & $\mathrm{n}$ & Mean & SD & $\mathrm{n}$ & Mean & SD & $n$ & Mean & SD & $\mathrm{n}$ & Mean & SD \\
\hline Age (years)* & 125 & 11.80 & 1.31 & 59 & 12.22 & 1.49 & 66 & 11.42 & 1.01 & 87 & 12.11 & 1.33 & 38 & 12.22 & 1.29 \\
\hline Body weight $(\mathrm{kg})^{*}$ & 125 & 46.86 & 11.97 & 59 & 50.50 & 13.60 & 66 & 43.60 & 9.25 & 87 & 45.75 & 12.44 & 38 & 49.40 & 10.54 \\
\hline Height $(\mathrm{cm})^{*}$ & 125 & 147.94 & 14.34 & 59 & 152.23 & 16.66 & 66 & 144.10 & 10.62 & 87 & 146.90 & 14.90 & 38 & 150.31 & 12.83 \\
\hline BMI $\left(\mathrm{kg} / \mathrm{m}^{2}\right)$ & 125 & 21.17 & 3.09 & 59 & 21.50 & 3.13 & 66 & 20.88 & 3.06 & 87 & 20.94 & 3.29 & 38 & 21.71 & 2.56 \\
\hline 6WRT $(\mathrm{m})^{*}$ & 125 & 929.50 & 166.00 & 59 & 1006.63 & 174.22 & 66 & 860.56 & 123.53 & 87 & 940.87 & 170.32 & 38 & 903.47 & 154.68 \\
\hline$\dot{V} O_{2 \text { peak }}[(\mathrm{mL} / \mathrm{kg}) / \mathrm{min}]^{*}$ & 125 & 44.49 & 5.78 & 59 & 47.03 & 5.877 & 66 & 42.23 & 4.69 & 87 & 44.95 & 6.11 & 38 & 43.44 & 4.87 \\
\hline
\end{tabular}

BMI: body mass index; 6WRT: 6-minute walk/run test; $\mathrm{V}_{\mathrm{O}_{2 \text { peak }}}$ : peak oxygen uptake; ${ }^{*}$ gender difference $p<0$.05.

Based on the results of gender comparison and correlation analyses, gender, BMI and 6WRT were included as independent variables in the linear regression model to predict $\dot{V} \mathrm{O}_{2 \text { peak }}$. The results showed that the best model to predict $\dot{V} \mathrm{O}_{2 \text { peak }}$ in the validation group included 6WRT, BMI and gender (Table 2). These variables showed a multiple correlation coefficient (R) of

0.77 and SEE of $3.99[(\mathrm{~mL} / \mathrm{kg}) / \mathrm{min}]$.

The equation that best predicted $\dot{V} \mathrm{O}_{2 \text { peak }}$ was: 


$$
\left.\dot{V} \mathrm{O}_{2 \text { peak }}=41.946+0.022(6 \mathrm{WRT})-0.875(\mathrm{BMI})+2.107 \text { (gender }\right)
$$

where: female gender is equal to 0 and male gender is equal to 1 ; variable units are expressed in $(\mathrm{mL} / \mathrm{kg}) / \mathrm{min}$ for $V \mathrm{O}_{2 \text { peak }}$, meters for the $6 \mathrm{WRT}$ and $\mathrm{kg} / \mathrm{m}^{2}$ for $\mathrm{BMI}$; the mean difference between measured and estimated $V O_{2 \text { peak }}$ values was $-0.43[(\mathrm{~mL} / \mathrm{kg}) / \mathrm{min}]$.

TABLE 2 - Linear regression model to predict peak oxygen uptake in adolescents age 10 to 14 from the 6-minute walk/run test, body mass index and gender in the validation group.

\begin{tabular}{|c|c|c|c|c|c|c|}
\hline Variables & Value & $95 \% \mathrm{Cl}$ & $\mathrm{p}$-value & $\mathrm{R}$ & $\mathrm{R}^{2}$ & SEE \\
\hline \multicolumn{4}{|l|}{ Model 1} & \multirow{3}{*}{0.59} & \multirow{3}{*}{0.35} & \multirow{3}{*}{4.95} \\
\hline Intercept & 25.006 & 19.039 to 30.966 & 0.000 & & & \\
\hline 6WRT & 0.021 & 0.015 to 0.027 & 0.000 & & & \\
\hline \multicolumn{4}{|l|}{ Model 2} & \multirow{4}{*}{0.75} & \multirow{4}{*}{0.55} & \multirow{4}{*}{4.08} \\
\hline Intercept & 40.236 & 33.447 to 47.025 & 0.000 & & & \\
\hline 6WRT & 0.025 & 0.019 to 0.030 & 0.000 & & & \\
\hline BMI & -0.880 & -1.151 to 0.609 & 0.000 & & & \\
\hline \multicolumn{7}{|l|}{ Model 3} \\
\hline Intercept & 41.946 & 35.110 to 48.781 & 0.000 & \multirow{4}{*}{0.77} & \multirow{4}{*}{0.58} & \multirow{4}{*}{3.99} \\
\hline 6WRT & 0.022 & 0.016 to 0.027 & 0.000 & & & \\
\hline BMI & -0.875 & -1.140 to 0.609 & 0.000 & & & \\
\hline Gender & 2.107 & 0.154 to 4.061 & 0.035 & & & \\
\hline
\end{tabular}

6WRT: 6-minute walk/run test; BMI: body mass index; $95 \% \mathrm{Cl}$ : $95 \%$ confidence interval; $p$ : significance level; R: multiple correlation coefficient; $R^{2}$ : determination coefficient; SEE: standard error of estimate.

When the equation created in the validation group was applied in the cross-validation group and total sample, the accuracy of the model was confirmed. Table 3 shows multiple correlation coefficients (R), coefficients of determination $\left(\mathrm{R}^{2}\right)$ and SEE of estimated $\dot{V} \mathrm{O}_{2 \text { peak }}$ in the cross-validation group and total sample. The mean difference between measured and estimated $\dot{V} \mathrm{O}_{2 \text { peak }}$ values were lower than $0.4[(\mathrm{~mL} / \mathrm{kg}) / \mathrm{min}]$ in the cross-validation group and total sample (Table 3).

TABLE 3 - Correlation coefficient and standard error of estimate measures and mean difference between measured and estimated peak oxygen uptake in the cross-validation group and total sample.

\begin{tabular}{lcc}
\hline & Cross-validation group & Total sample \\
\hline $\mathrm{N}$ & 38 & 125 \\
\hline Estimated $\dot{V} \mathrm{O}_{2 \text { peak }}($ mean $\pm \mathrm{SD})$ & $43.66 \pm 4.19[(\mathrm{~mL} / \mathrm{kg}) / \mathrm{min}]$ & $44.86 \pm 4,64[(\mathrm{~mL} / \mathrm{kg}) / \mathrm{min}]$ \\
\hline Mean difference $(95 \% \mathrm{LA})$ & $-0.22(-8.02 ; 7.58)$ & $-0.37(-8.17 ; 7.43)$ \\
\hline $\mathrm{R}$ & 0.64 & 0.74 \\
\hline $\mathrm{R}^{2}$ & 0.41 & 0.55 \\
\hline $\mathrm{SEE}$ & 3.80 & 3.90 \\
\hline
\end{tabular}

$\dot{V}_{\mathrm{O}_{2 \text { peak }}}$ : peak oxygen uptake; n: sample; SD: standard deviation; LA: limits of agreement (mean difference $\pm 1.96 \mathrm{SD}$ of the difference); R: correlation coefficient between measured and estimated peak oxygen uptake measures; $R^{2}$ : determination coefficient; SEE: standard error of estimate.

The Figure (a and b) shows the agreement (Bland-Altman plots) between measured and estimated $\dot{V} \mathrm{O}_{2 \text { peak }}$ values in the validation and cross-validation groups. The results indicate that the proposed equation to estimate $\dot{V} \mathrm{O}_{2 \text { peak }}$ shows no systematic bias $(p<0.05)$, and there was no association of the differ- 
ence between measured and estimated $\dot{V} \mathrm{O}_{2 \text { peak }}$ values with mean measured and estimated $\dot{V} \mathrm{O}_{2 \text { peak }}$ values $(p<0.05)$ in both validation and cross-validation groups.
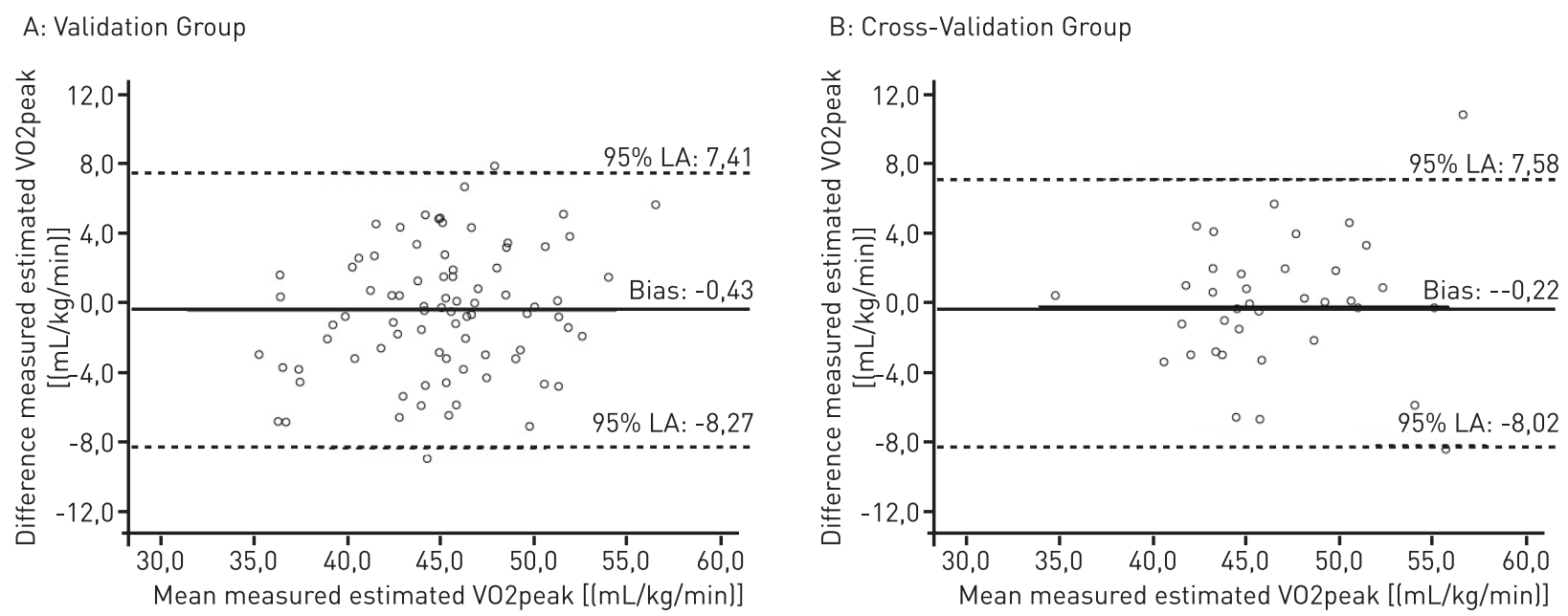

FIGURE 1 - Agreement between measured and estimated peak oxygen uptake measures in the validation (Figure a) and cross-validation groups (Figure b). The solid line represents the mean difference (bias) between measured and estimated peak oxygen uptake measures. Upper and lower dashed lines represent the $95 \%$ limits of agreement (mean difference \pm 1.96 SD).

\section{DISCUSSION}

Our study proposed a new regression equation to estimate $\dot{V} \mathrm{O}_{2 \text { peak }}$ from $6 \mathrm{WRT}, \mathrm{BMI}$ and gender in adolescents age 10-14. The equation was created in a validation group and then tested in a cross-validation one. The results indicated that the new equation is valid to predicting $\dot{V} \mathrm{O}_{2 \text { peak }}$. This is a major contribution as it allows to measuring and monitoring CRF in adolescents using a short test to estimate $\dot{V} \mathrm{O}_{2 \text { peak }}$.

The results of our study are consistent with those of previous studies proposing an equation to predict $\dot{V} \mathrm{O}_{2 \text { peak }}[(\mathrm{mL} / \mathrm{kg}) / \mathrm{min}]$ from indirect field tests. The mean results of the 6WRT for gender found in our study are similar to those reported by Van Mechelen et al. ${ }^{14}$ showing that males had better test performance than females. However, the mean distances covered in the 6WRT in Van Mechelen et al. ${ }^{14}$ study were greater than those in our study. This difference can be explained by not only sociocultural factors but also temporal aspects as secular trend studies showed that CRF of adolescents decreased in recent decades. ${ }^{14}$

$\dot{V} \mathrm{O}_{2 \text { peak }}$ values found in our study are similar to ${ }^{16-19}$ or lower than ${ }^{3,14,20-23}$ those reported in other studies. Regardless of the magnitude of mean $\dot{V} \mathrm{O}_{2 \text { peak }}$ values reported in the above mentioned studies, $\dot{V} \mathrm{O}_{2 \text { peak }}$ was higher in males $(p<0.05)$ than females. This finding supports the inclusion of the gender variable into equations to predict $\dot{V} \mathrm{O}_{2 \text { peak }}$ in adolescents or specific equations for each gender.

A slightly lower correlation coefficient measure was found between $\dot{V} \mathrm{O}_{2 \text { peak }}$ and the 6WRT in the present study than that described in Van Mechelen et al. ${ }^{14}$ study. The correlation coefficient measures between $\dot{V} \mathrm{O}_{2 \text { peak }}$ and different 
walk/run field tests in children and adolescents range from 0.50 to $0.85^{24-26}$ suggesting that walk/run field tests have a moderate to strong capacity to predict $\dot{V} \mathrm{O}_{2 \text { peak }}$ in children and adolescents. This piece of evidence supports the approach used in this study and other studies to include other variables associated to the run/walk field test to enhance the predictive capacity of $\dot{V} \mathrm{O}_{2 \text { peak }}$.

Other studies have used regression models to predict $\dot{V} \mathrm{O}_{2 \text { peak }}$ from indirect field tests and other variables including gender, age, body weight, height, BMI and skinfold in samples of participants similar in age to those in our study. The indirect field test that has been most explored is the SRT and several approaches have been proposed especially those described by Mahar et al. ${ }^{18}$ Barnett et al., ${ }^{20}$ Matsuzaka et al. ${ }^{23}$ and Léger et al. ${ }^{27}$ The $1-M W T$ test was used in two proposed approaches. ${ }^{17,28} \mathrm{We}$ did not found any other study that used $6 \mathrm{WRT}$ to predict $\dot{V} \mathrm{O}_{2 \text { peak }}$. Nevertheless, Castro-Pinero et al. ${ }^{3}$ proposed an approach to predict $\dot{V} \mathrm{O}_{2 \text { peak }}$ from a short test, the $1 / 2$-mile walk test $(1 / 2-M W T)$. The multiple correlation coefficient and standard SEE measures found in the above studies were similar to those found in our study (Table 4).

TABLE 4 - Multiple correlation coefficient and standard error of estimate measures of different regression models for predicting peak oxygen uptake in children and adolescents.

\begin{tabular}{|c|c|c|c|c|c|}
\hline Proposed approaches & Age & Field test & Other variables & $\mathrm{R}$ & SEE \\
\hline Castro-Pinero et al. ${ }^{5}$ & $10-17$ & $1 / 2-M W T$ & Gender and $\mathrm{BMI}$ & 0.66 & 4.40 \\
\hline Mahar et al. ${ }^{17}$ & $10-16$ & SRT & Gender, age, BMI and laps & 0.75 & 6.17 \\
\hline Barnett et al. ${ }^{19}$ & $12-17$ & SRT & $\begin{array}{l}\text { Equation 1) gender, skinfold and } \\
\text { speed; Equation 2) gender, body } \\
\text { weight and speed; Equation 3) } \\
\text { gender, age and speed }\end{array}$ & $\begin{array}{l}0.85 \\
0.84 \\
0.82\end{array}$ & $\begin{array}{l}3.70 \\
3.70 \\
4.00\end{array}$ \\
\hline Matsuzaka et al. ${ }^{22}$ & $08-17$ & SRT & $\begin{array}{c}\text { Equation 1) gender, age, BMI and } \\
\text { speed; Equation 2) gender, age, } \\
\text { BMI and laps }\end{array}$ & $\begin{array}{l}0.81 \\
0.80\end{array}$ & $\begin{array}{l}3.30 \\
3.40\end{array}$ \\
\hline Léger et al. ${ }^{26}$ & $08-19$ & SRT & Speed and age & 0.71 & 5.90 \\
\hline Cureton et al. ${ }^{16}$ & $08-17$ & 1-MWT & Gender, age and BMI & 0.71 & 4.78 \\
\hline Buono et al. ${ }^{27}$ & $10-18$ & 1-MWT & Gender, skinfolds and body weight & 0.84 & 4.30 \\
\hline Present study & $10-14$ & 6WRT & Gender and $\mathrm{BMI}$ & 0.77 & 3.99 \\
\hline
\end{tabular}

* Mean age and (standard deviation); SRT: 20-meter shuttle run test; 1-MRV: one mile run/walk test; 6WRT: 6-minute run/walk test; BMI: body mass index; R: multiple regression coefficient; SEE: standard error of estimate.

Although the propositions using the SRT showed the highest correlation coefficient and lowest SEE measures, Ruiz et al. ${ }^{29}$ showed that, except for Barnett et al. ${ }^{20}$ proposed approach, these approaches tend to underestimate $\dot{V} \mathrm{O}_{2 \text { peak }}$. In addition, as the running speed increase at the end of each stage, children and adolescents should be familiarized with the SRT to ensure that the results can be used to predict $\dot{V} \mathrm{O}_{2 \text { peak }}$. However, all proposed approaches to predict $\dot{V} \mathrm{O}_{2 \text { peak }}$ presented valid estimates.

About the approaches using the 1-MWT test, both presented valid predicted $\dot{V} \mathrm{O}_{2 \text { peak }}$ estimates. However, despite finding a lower multiple correlation coefficient than that reported by Buono et al. ${ }^{28}$ Cureton et al. ${ }^{17}$ proposed approach is the most widely used to predict $\dot{V} \mathrm{O}_{2 \text { peak }}$ and is recommended for Fitnessgram..$^{10}$ Castro-Piñero et al. ${ }^{3}$ approach using the $1 / 2-M W T$ also showed a valid estimate to predict $\dot{V} \mathrm{O}_{2 \text { peak }}$ but it is a recently proposed equation based on an underused test. A comparison of our results to the literature showed 
similar correlation coefficients and SEE values suggesting that our approach can be an adequate estimate to predict $\dot{V} \mathrm{O}_{2 \text { peak }}$ in adolescents.

Similar to the $1 / 2-M W T$, the 6WRT is not an indirect field test frequently used to measure CRF in adolescents. It has a limited use as show by Van Mechelen et al. ${ }^{14}$. They studied 82 adolescents (41 females) age 12-14 and compared the correlation coefficients for $\dot{V} \mathrm{O}_{2 \text { peak }}$ between SRT and 6WRT with those directly measured during maximal treadmill running. They found higher correlation coefficient measures for SRT.

Although the 6WRT is not commonly used in studies on CRF in adolescents, its use has some advantages, similar to those reported for the $1 / 2-M W T$, as described by Castro-Piñero et al. $^{3}$ it is a short test that allows adolescents to keep running at the same pace and stay motivated during test performance.

In our study, the Bland-Altman method was applied to test the agreement between measured and estimated $\dot{V} \mathrm{O}_{2 \text { peak }}$ because this technique has been used to test agreement between two measures in recent studies. ${ }^{3,21}$. Our results showed no difference $(p>0.05)$ between measured and estimated $\dot{V} \mathrm{O}_{2 \text { peak }}$ (systematic bias) in the validation and cross-validation groups. Moreover, no association $(p>0.05)$ was found between the difference and the magnitude of measurement (heteroscedasticity) in both groups. These findings, together with the linear regression results (R and SEE), reinforce the validity of our regression equation to estimate $\dot{V} \mathrm{O}_{2 \text { peak }}$ from the $6 \mathrm{WRT}, \mathrm{BMI}$ and gender in adolescents age 10-14.

Our study has some limitations that need to be considered. First, our study used a sample of adolescents age 10 to 14 but most studies have investigated individuals age 7 to 17 . And second, some variables were not explored in the study. As suggested by Castro-Pinero et al., ${ }^{3}$ the $6 \mathrm{WRT}$ performance can be affected by genetic and behavioral factors, and running economy. Despite these limitations, our findings are representative and provide an alternative approach to predict $\dot{V} \mathrm{O}_{2 \text { peak }}$ in adolescents from primary outcome variables including the 6WRT, BMI and gender.

In conclusion, the equation created by linear regression analysis including the $6 \mathrm{WRT}, \mathrm{BMI}$ and gender has adequate power. Moreover, the correlation coefficients, SEE, systematic bias and heteroscedasticity found in our study are similar those reported in other studies that proposed equations to predict $\dot{V} \mathrm{O}_{2 \text { peak }}$ from different indirect field tests to measure CRF. Finally, our study fills a gap in the literature by providing an alternative equation to predict $\dot{V} \mathrm{O}_{2 \text { peak }}$ from the $6 \mathrm{WRT}$ in adolescents.

\section{Authors' contribution}

GGB helped in all steps of the study. MLAB and AAMC were involved in decisions about methodology and reviewed all steps of the study. TDCL, ESP and RBM helped data collection and were involved in decisions about methodology. ACM and ACAG supervised and reviewed all steps of the study.

\section{REFERENCES}

1. Lobelo F, Pate RR, Dowda M, Liese AD, Daniels SR. Cardiorespiratory fitness and clustered cardiovascular disease risk in U.S. adolescents. J Adolesc Health. 2010;47(4):352-9. 
2. Bergmann GG, Gaya ACA, Halpern R, Bergmann MLA, Rech RR, Constanzi CB et al. Cardiorespiratory fitness cut offs points and cardiovascular risk factors screening at infancy. Rev Bras Med Esporte. 2010;16(5)339-43.

3. Castro-Piñero J, Ortega FB, Mora J, Sjöström M, Ruiz JR. Criterion related validity of 1/2 mile run-walk test for estimating VO2peak in children aged 6-17 years. Int J Sports Med. 2009;30(5):366-71.

4. Armstrong N, Barker AR. Oxygen uptake kinetics in children and adolescents: a review. Pediatr Exerc Sci. 2009;21(2):130-47.

5. Fawkner SG, Armstrong N. Oxygen uptake kinetic response to exercise in children. Sports Med. 2003;33(9):651-69.

6. Ruiz JR, Castro-Piñero J, España-Romero V, Artero EG, Ortega FB, Cuenca MM, et al. Field-based fitness assessment in young people: the ALPHA health-related fitness test battery for children and adolescents. Br J Sports Med. 2011;45(6):518-24.

7. Adam C, Klissouras V, Ravazzolo M, Reson R, Tuxworth W. EUROFIT: Eurofit Test of Physical Fitness. Council of Europe, Committee for the Development of Sport. Rome: Edigraf Editoriale Grafica, 1988.

8. Kemper HCG, Verschuur R, Bovend'eerdt J. The Moper Fitness Test 1: a practical approach to motor performance test in physical education in the Netherland. S AJ Res Sport Phys Ed Recr. 1979;2(1):81-90.

9. Meredith MD, Welk GJ. Fitnessgram / Activitygram test administration manual. Update 4th. ed. Champaign Il: Human Kinetics, 2010.

10. PROJETO ESPORTE BRASIL. Available in: //http://www.proesp.ufrgs.br/proesp/.

11. Lohman TG, Roche AF, Martorell R. Anthropometric standardization reference manual. Champaign Il: Human Kinetics, 1988.

12. Cunha G, Lorenzi T, Sapata K, Lopes AL, Gaya AC, Oliveira A. Effect of biologic maturation on maximal oxygen uptake and ventilatory thresholds in soccer players: An allometric approach. J Sports Sci. 2011;29(10):1029-39.

13. Karila C, Blic J, Waerbessyckle S, Bernoist M, Scheinmann P. Cardiopulmonary exercise testing in children: an individualized protocol for workload increase. Chest. 2001;120(1):81-7.

14. Van Mechelen W, Hlobil H, Kemper HC. Validation of two running tests as estimates of maximal aerobic power in children. Eur J Appl Physiol Occup Physiol. 1986;55(5):503-6.

15. Tomkinson GR, Olds TS. Secular changes in pediatric aerobic fitness test performance: the global picture. Med Sport Sci. 2007;50:46-66.

16. Rodrigues AN, Perez AJ, Carletti L, Bissoli NS, Abreu GR. Maximum oxygen uptake in adolescents as measured by cardiopulmonary exercise testing - a classification proposal. J Pediatr. 2006;82(6):426-30.

17. Cureton KJ, Sloniger MA, O’Bannon JP, Black DM, McCormack WP. A generalized equation for prediction of $\mathrm{VO}_{\text {2peak }}$ from 1-mile run/walk performance. Med Sci Sports Exerc. 1995;27(3):445-51.

18. Mahar MT, Guerieri AM, Hanna MS, Kemble CD. Estimation of aerobic fitness from 20-m multistage shuttle run test performance. Am J Prev Med. 2011;41(4 Suppl 2):S117-23.

19. Turley KR, Wilmore JH, Simons-Morton B, Williston JM, Epping JR, Dahlstron G. The Reliability and Validity of the 9-Minute Run in Third-Grade Children. Pediat Exerc Sci. 1994;6(2):178-87.

20. Barnett A, Chan L, Bruce I. A preliminary study of the 20-m multistage shuttle run as a prectictor of peak VO2 in Hong Kong Chinese students. Pediat Exerc Sci. 1993;5(1):42-50.

21. Castro-Piñero J, Mora J, Gonzalez-Montesinos JL, Sjostrom M, Ruiz JR. Criterionrelated validity of the one-mile run/walk test in children aged 8-17 years. J Sports Sci. 2009;27(4):405-13.

22. Garcia AW, Zakrajsek JS. Evaluation of the Canadian Aerobic Fitness Test with 10 to 15 year old children. Pediatr Exerc Sci. 2000;12(3):300-11.

23. Matsuzaka A, Takahashi Y, Yamazoe M, Kumakura N, Akiko I, Wilk B, et al. Validity of the multistage 20-m shuttle-run test for Japanese children, adolescents, and adults. Pediat Exerc Sci. 2004;16(2):113-25. 
24. Cureton KJ, Boileau RA, Lohman TG, Misner JE. Determinants of distance running performance in children: analysis of a path model. Res Q. 1977;48(2):270-9.

25. Jackson AS, Coleman AE. Validation of distance run tests for elementary schoolchildren. Res Q. 1976;47(1):86-94.

26. Krahenbhul GS, Pangrazi RP, Burkett LN, Schneider MJ, Petersen G. Field estimation of VO2max in children eight years of age. Med Sci Sports. 1977;9(1):37-40.

27. Léger LA, Mercie D, Gadoury C, Lambert J. The multistage 20 metre shuttle run test for aerobic fitness. J Sports Sci. 1988;6(2):93-101.

28. Buono MJ, Roby JJ, Micale FG, Sallis JF, Shepard WE. Validity and Reliability of Predicting Maximum Oxygen Uptake via Field Tests in Children and Adolescents. Pediatr Exerc Sci. 1991;3(3):250-55.

29. Ruiz JR, Ramirez-Lechuga J, Ortega F, Castro-Piñero J, Arouzo-Azofra A, Sanchez C, Sjöström M, Castillo MJ, Gutierrez A, Zabala M. Artificial neural network-based equation for estimating $\mathrm{VO} 2 \mathrm{max}$ from the $20 \mathrm{~m}$ shuttle run test in adolescents. Artif Intell Med. 2008;44:233-45.

CORRESPONDING AUTHOR

GABRIEL ANDRADE PAZ

Rua Arlete Ceslestina Ayres Wanderley,

450 - Jardim Sulacap, Rio de Janeiro,

RJ, Brasil. CEP: 21745-650.

(21) 99803-1514. 